\section{MOLECULAR PHYSICS IN HIGH VACUA ${ }^{1}$}

WHEN I was asked, a month or two ago, to illustrate in this theatie some of my recent researches on molecular physics in high vacua, I exclaimed, "How is it possible to bring such a subject worthily before a Royal Institution audience when none of the experiments can be seen more than three feet off?" If to-niglit $I$ am fortunate enough to show all the experiments to those who are not far distant, and if I succeed in maling most of them visible at the far end of the theatre, such a success will be entirely due to the great kindness of your late secretary, $\mathrm{Mr}$. Spottiswoode, who has placed at my disposal his magnificent induction-coil-not only for this lecture, but for some weeks past in my own laboratory-thus enabling ine to prepare apparatus and vacuum tubes on a scale so large as to relieve me of all anxiety so far as the experimental illustrations are concerned.

Before describing the special researches in molecular physics which I propose to illustrate this evening, it is necessary to give a brief ontline of one small department of the modern theory of the constitution of gases. It is not easy to make clear the kinetic theory, but I will try to simplify it in this way:-Imagine that I have in a large box a swarm of bees, each bee independent of its fellow, fiying about in all manner of directions and with very different velocities. The bees are so crowded that they can only fly a very short distance without coming into contact with one another or with the sides of the box. As they are constantly in collision, so they rebound from each other with altered velocities and in different directions, and when these collisions talie place against the sides of the box pressure is produced. If I take some of the bees out of the box, the distance which each individual bee will be able to fly before it comes into contact with its neighbour will be greater than when the box was full of bees; and if I remove a great many of the bees I increase to a considerable extent the average distance that each can fly without a collision. This distance I will call the bee's mean free path. When the bees are numerous the mean free path is very short; when the bees are few the mean free path will belonger, the length being inversely proportional to the number of bees present. Let us now inagine a loose diaphragun to be introduced in the centre of the box, so as to divide the number of bees equally. The same number of bees being on each sicle, the impacts on the diaphragm will be equal; and the mean speed of the bees being the same, the pressure will be identical on each side of the diaphrager, and it will not move.

Let me now warm one sice of this division so as to let it communicate extra energy to a bee when it touches it. As before, a bea will strike the diaphragin with its normal mean velocity, but will be driven back with extra velocity, the reaction producing air increase of pressure on the diaphragm. It will be found, however, that although the diaphragm is free to move, the extra strength of the recoil on the warm side does not pro. duce any motion. This at frrst sight seems contrary to the law of action and reaction being equal. The explanation is not difficult to anderstand. The bees which fly away from the diaphragin have drawn energy from it, and therefore move quicker than thcse which are coming towards it; they beat back the crowd to a greater distance, and keep a greater number from striking the diaphragn. Near to the heated side of the diaphragin the density is less than the average, while beyond the free path the density is above the average, and this greater crowding extends to all other parts of the box. Thus it happens that the extra energy of the impacts against the warm side of the diaphragm is exactly compensated by the increased number of impacts on the cool side. In spite therefore of the increased activity comminicated to a portion of the bees, the pressure on the two sides of the diaphragm will remain the same: This represents what occurs when the extent of the box containing the bees is so great, compared with the mean free path, that the abrupt change in the velocities of those bees which rebound from the walls of the box produces only an insensible influence on the motions of bees at so great a distance as the diaphragm.

I will next ask you to imagine that I am gradually removing bees from our box, still keeping the diaphragm warin on one side. The bees getting fewer the collisions will become less frequent, and the distance each bee can fly before striling it: neighbour will get longer and longer, and the crowding in front of them will grow less and less. The compensation will also diminish, and the warmed side of the diaphragm will have a

IA short-hand report of a lecture delivered at the Royal Institution on Friday, April 4, r879. By William Crookes, F.R.S. Contributed by the author. tendency to be beaten back. A point will at last be reached on the warm side, when the mean free path of the bees will be long enough to admit of their dashing right across frotu the diaphragm to the side of the box, without meeting more than a certain number of in-coming bees in their flight. In this case the bees will no longer fly quite in the same direction as before. They will now fly less sideways, and more forwards and backwards between the heated face of the diaphragm and the opposed wall of the box. Because of this preponderating motion, and also because they will thereby less effectually keep back bees crowding in from the sides, there will now be a greater proportionate

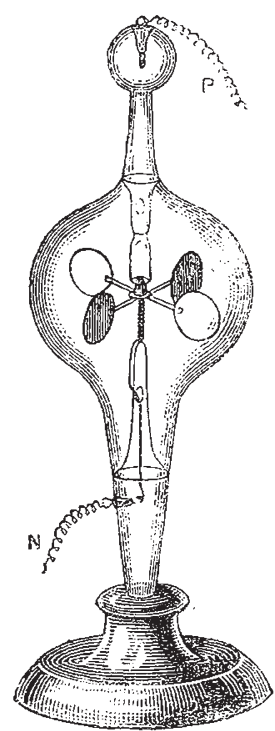

FIG. I. pressure both on the hot face of the diaphragm and on that part of the box which is in front of it. Hence the pressure on the hot side will now exceed that on the cool side of the diaphragm, which will consequently have a backward movement communicated to it.

I may diminish the size of the bees as much as I like, and by correspond. ingly increasing their number the mean free path will remain the same. In. stead of bees let me call them molecules, and instead of having a few hundreds or thousands in the box let me have millions and billions and trillions; and if we also diminish the mean free path to a considerable extent, we get a rougl outline of the linetic theory of gases. (I may just mention that the mean free path of the molecules in air, at the ordinary pressure, is the ten-thousandth of a millimetre.)

Three years ago I had the honoul of bringing before you the results of some researches on the radiometer. Iet me now take up the subject where I then left off. I have here two radiometers which have been rotating Eefore you under the influence of a strong light shining mpon them.

The explanation of the movement of the radiometer is thisthe light, or the total bundle of rays included in the term "light," falling upon the blackened side of the vames, becomes absorbed, and thereby raises the temperature of the black side: this causes extra excitement of the air molecules which come in contact with it, and pressure is produced, causing the fly of the radiometer to turn rotund.

I have long believed that a well-known appearance obseived in vacuum tubes is closely related to the phenomena of the mear

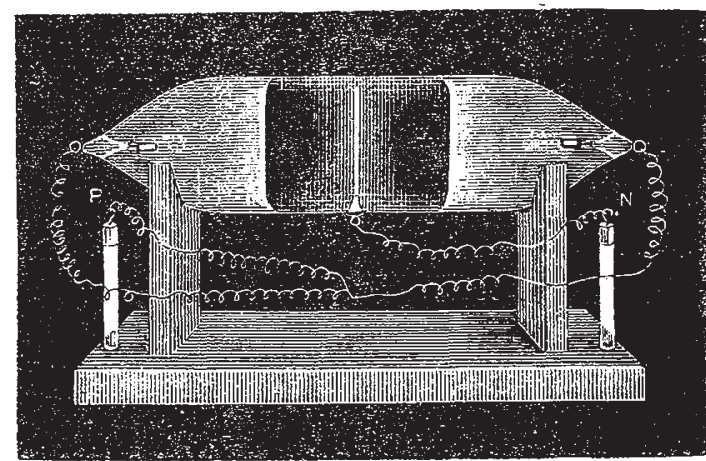

FIG. 2.

free path of the molecules. When the negative pole is examined while the discharge from an induction coil is passing through an exhausted tube, a dark space is seen to surround it. This dark space is fornd to increase and diminish as the vacuum is varied, in the same way that the ideal layer of molecular pressure in the radiometer increases and diminishes. As the one is perceived by the mind's eye to get greater, so the other is seen by the bodily eye to increase in size. If the vacuum is insuficient to permit the radiometer to turn, the passage of electricity shows 
that the "dark space" has shrunk to suall dimensions. It is a natural inference that the dark space is the mean free path of the molecule; of the residual gas.

The radiometer which has just been turning under the influence of the lime-light is not of the ordinary kind. Fig. I will explain its constraction.

It is similar to an ordinary radiometer with aluminium disks for vanes, each disk coated on one side with a film of mica. The fly is supported by a hard steel instead of glass cup, and the needle point on which it works is conmected by means of a vire with a platinum terminal sealed into the glass. At the top of the radiometer bulb a second terminal is sealed in. The radiometer can therefore be connected with an induction-coil, the movable fly being made the negative pole.

As soon as the pressure is reduced to a few millims. of mercury, a halo of velvety violet light forms on the metallic side of the vanes, the mica side remaining darl. As the pressure diminishes, a dark space is seen to separate the violet halo from the metal. At a pressure of half a millin. this dark space extends to the glass, and positive rotation commences. On continuing the exhatustion the dark space further widens out and appears to fiatten itself against the glass, when the rotation becouses very rapid.

You perceive a dark space behind each vane and moving round with it. In the first experiment, radiation from the limelight falling on the metallic sides of the vanes, produced a layer of molecular pressure which drove the fly round; so here the induction-current has produced molecular excitement at the surface of the vanes forming the negative pole, extending up to the side of the glass.

When the negative pole is in rapid rotation it is not easy to see this dark space, so I have arranged a tube in which the dark space will be visible to all present. The tube, as you will see $\mathrm{t}$ the diagram (Fig. 2), has a pole in the centre in the form of a metal disk, and other poles at each end. The centre pole is made negative, and the two end poles connected together are made the positive terminal. The dark space will be in the centre. When the exhaustion is not very great the dark space extends only a little distance on each side of the negative pole in the centre. When the exhaustion is very good, as it is in the tube before you, and I turn on the coil, the dark space is seen to extend for about two inches on each side of the pole.

Here, then, we see the induction spark actually illuminating the lines of molecular pressure caused by the excitement of the negative poie. The thickness of this dark space-nearly two inches-is the measure of the mean free path between successive collisions of the molecules of the residual gas. The extra velocity with which the negatively electrified molecules rebound from the excited pole keeps back the more slowly moving molecules which are advancing towards that pole. The conflic occurs at the boundary of the dark space, where the luninous margin bears witness to the energy of the discharge.

I will encleavour to throw on the screen an illustration of this dark space. A stream of water falls from a small jet on to a horizontal plate of glass. The water spreads over the plate and forms a thin film. The jet of water in the centre, from the velocity of its fall, drives the film of water before it on all sides, raising it into a ring-shaped heap. As I diminish the force of the jet the ring contracts; this is equivalent to the exhaustion getting less. When I increase the force of water the ring expands in size, the effect being analogons to an increase of exhaustion in my tubes. The extra velocity of the falling particles of water drives the in-coming particles of water before them, and raises a ridge round the side which exactly represents the luminous halo to the dark space to be seen in this tube.

If, instead of a flat disk, a metal cup is used for the negative pole, the successive appearances on exlatisting the tube are somewhat different. The velvety violet halo forms over each side of the citp. On increasing the exhaustion the dark space widens out, retaining almost exactly the shape of the cup. The bright margin of the dark space becomes concentrated at the concave side of the cup to a luminous focus, and widens out at the convex side. When the dark space is very much larger than the cup, its outline forms an irregular ellipsoid drawn in towards the focal point. Inside the lumainous bonndary a dark violet light can be seen converging to a focus, and, as the rays diverge on the other side of the focus, spreading beyond the margin of the dark space; the whole appearance being strikingly similar to the rays of the sun reflected from a concave mirror through a foggy atmosphere. This proves a somewhat important point; it shows that the molecules thrown off the excited negative pole leave it in a direction almost normal to the surface.

I can illustrate this property of the molecular rays by an experiment. This diagram (Fig. 3 ) is a representation of the tube which is before you. It contains, as a negative pole, a hemi-cylinder $(a)$ of polished aluminium. This is connected with a fine copper wire, $b$, ending at the platinum terminal, $c$.

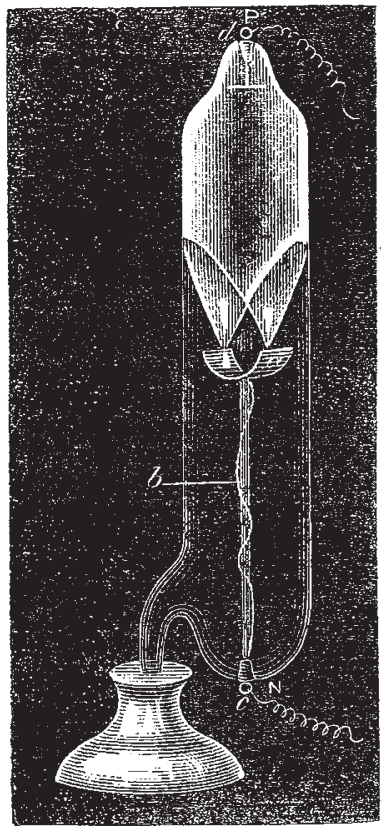

FIg. 3 .

At the upper end of the tube is another terminal, $d$. The induction-coil is connected so that the hemi-cylinder is negative and the upper pole positive, and when exhausted to a sufficient extent, as is the case with this tube, the projection of the molecular rays to a focus is very beautifully shown. The rays are driven from the hemi-cylinder in a direction normal to its surface; they come to a focus and then diverge, tracing their path in brilliant green phosphorescence on the surface of the glass.

You will notice that the rays which project from the negative pole and cross in the centre have a bright green appearance; that colour is entirely due to the phosphorescence of the glass. At a very high exhaustion the phenomena noticed in ordinary vacuum tubes when the induction spark passes through them-an appearance of cloudy luminosity and of stratifications-cisappears entirely. No cloud or fog whatever is seen in the body of the tube, and with such a vacuum as I am working with in these experiments-about a millionth part of an atmosphere-the inner surface of the glass glows with a rich green phosphorescence, the intensity of colour varying with the perfection of the vacuum, It scarcely begins to show much before the SoJ, oooth of an atmosphere. At about a millionth of an atmosphere the phos. phorescence is very strong, and after that it begins to diminish

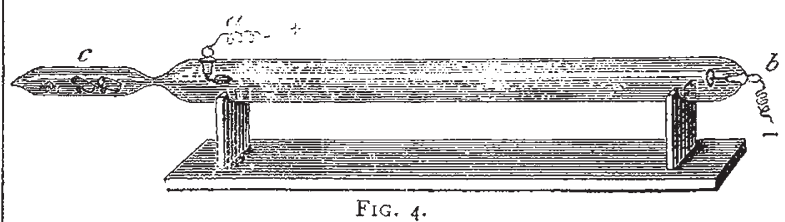

until there are not enough molecules left to allow the spark to pass. $^{I}$

I have here a tube which will serve to illustrate the dependence of the green phosphorescence of the glass on the degree of perfection of the vacuum (Fig. 4). The two poles are at $a$ and $\mathrm{r}$ \% millionth of an atmosphere $=0.0007$ millim.
$\mathrm{r} 3 \times 5.789$ millionths of an atmosphere
$\mathrm{x}, 000,000 \quad, \quad, \quad=760^{\circ} \circ \mathrm{millims}$


$b$, and at the end $(c)$ is a small supplementary tube connected with the other by a narrow aperture, and containing solid caustic potash. The tube has been exhausted to a very high point, and the potash heated so as to drive off moisture and deteriorate the

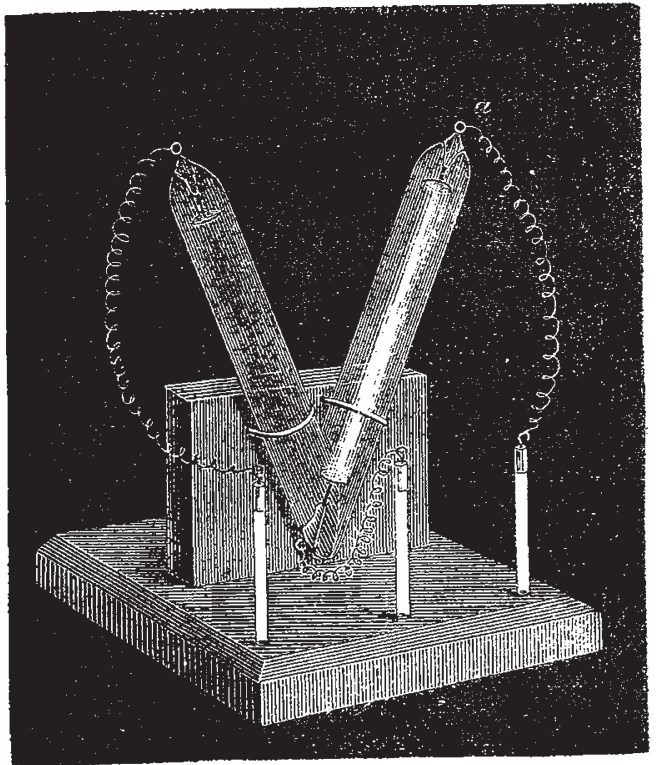

K'IG. 5 .

vacuar. Exhaustion has then keen re-commenced, and the

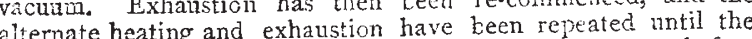
alternate heating and exhaustion have tube has been brought to the sta'e in which it now appears before
you. When the induction spark is furst turised on nothing is visible-the vacuum is so high that the tube is non-conducting. I now warm the potash slightly, and liberate a trace of aqueous vapour. Instantly conduction commences, and the green phosphorescence flashes out along the length of the tube. I continue the heat, so as to drive off more gas from the potash. The green gets fainter, and now a wave of cloudy luminosity sweeps over the tube, and stratifications appear. These rapidly get narrower, until the spark passes along the tube in the form of a narrow purple line. I take the lamp away, and allow the potash to cool; as it cools, the aqueouts vapour, which the heat had driven off, is re-absorbed. The purple line broadens out, and breaks up into fine stratifications; these get wider, and travel towards the potash tube. Now a wave of green light appears on the glass at the other end, sweeping on and driving the last pale stratification into the potash; and now the tube glows over its whole length with the green phosphorescence. Would time allow I might keep it before you, and show the green growing fainter and the vacuum becoming non-conducting; but time is required for the absorption of the last traces of vapour by the potash, and I must pass on to the next subject.

This green phosphorescence is a subject that has much occilpied my thoughts, and I have striven to ascertain some of the laws governing its orcurrence. I soon perceived that the phosphorescence was not in the body of the tube itself, but was entirely on the surface of the glass. Another peculiarity of the rays producing this green phosphorescence is that they will not turn a comer in the slightest degree. Here is a V-shaped tube (Fig. 5), a pole being at each extremity. The pole at the right side $(a)$ being negative, you see that the whole of the right arm is flooded with green light, but at the bottom it stops sharply, and will not turn the corner to get into the left side. When I reverse the current, and make the left pole negative, the green changes to the left side, always following the negative pole, leaving the positive side with scarcely any luminosity.

In the ordinary phenomena exhibited by vacuum tubesphenomena with which we are all familiar-it is customary, for the more striking illustration of their contrasts of colour, to have the tubes bent into very elaborate designs. The positive luminosity caused by the phosphorescence of the residual gas follows all the convolutions and designs into which skilful glass-blowers

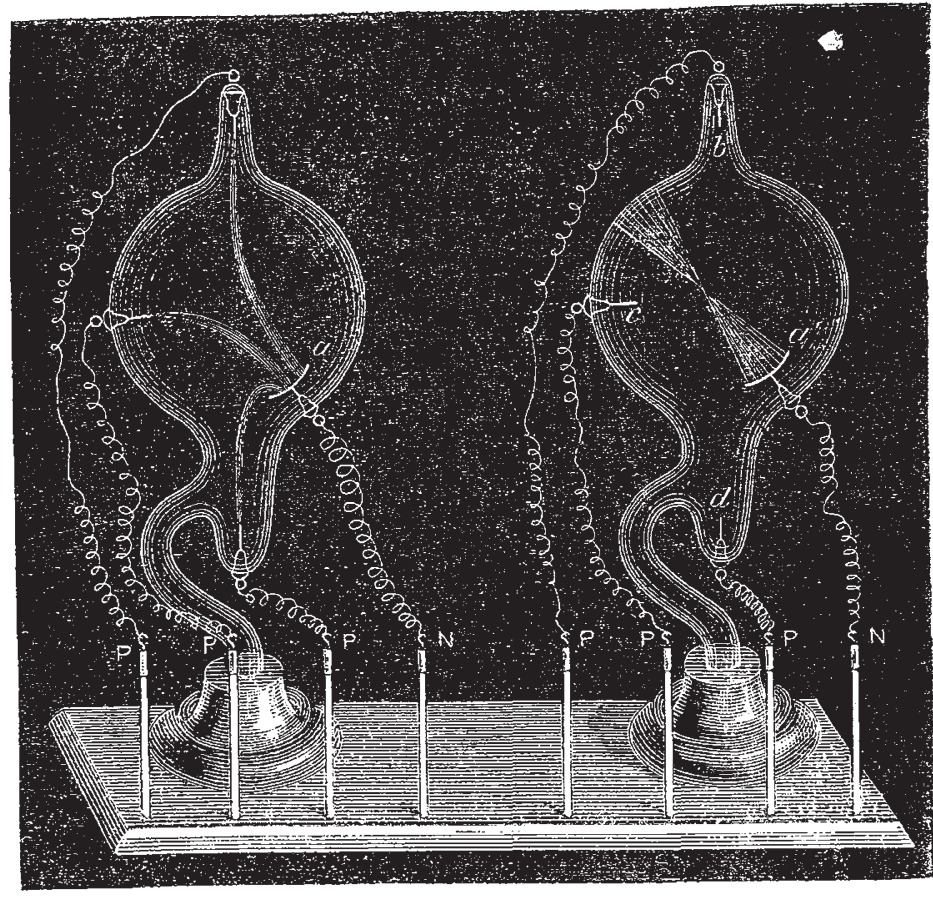

FIG. 6.

can manage to twist the glass. The negative pole being at one / best phenomena of vacuum tubes. I have here two bulbs (Fig. 6), end and the other, the luminous phenomena alike in shape and position of poles, the only difference being end and the positive pole at the other, the luminous phenomena alike in shape and postion of poles, the millimetres of mercury seem to depend more on the positive than on the negative at an that one is at an exhaustion equal to a few millmetres of mercury 
ordinary luminous phenomena-whilst the other is exhausted to about the millionth of an atmosphere. I will first connect the moderately exhausted bulb with the induction-coil, and, retaining the pole at one side $(a)$ always negative, I will put the positive wire successively to the other three poles with which the bulb is furnished. You will see that as 1 change the position of the positive pole, the line of violet light joining the two poles changes. In this moderately exhausted bulb, therefore, the electric current always chooses the shortest path between the two poles, and moves about the bulb as I alter the position of the wires.

This, then, is the kind of phenomenon we get in ordinary exhaustions. I will now try the same experiment with a tube that is highly exhausted, and, as before, will make the side pole $\left(a^{\prime}\right)$ the negative, the top pole (b) being positive. Notice bow widely different is the appearance from that shown by the last bulb. The negative pole is in the form of a shallow cup. The bundle of rays from the cup crosses in the centre of the bulb, and thence diverging, falls on the opposite side as a circular patch of green light. As I turn the bulb round you will all be able to see the faint blue focus and the green patch on the glass. Now observe, I remove the positive wire from the top, and connect it with the side pole $(c)$. The green patch from the divergent negative focus is still there. I now make the lowest pole (d) positive, and the green patch still remains where it was at first, unchanged in position or intensity.

'This, then, gives us another fact which brings us a little nearer to the cause of this green phosphorescence. It is this-that in the low vacuum the position of the positive pole is of every importance, whilst in a high vacuum it scarcely matters at all where the positive pole is; the phenomena seem to depend entirely on the negative pole. In very high vacua, such as we have been using, the phenomena follow altogether the negative pole. If the negative pole points in the direction of the positive, all very well, but if the negative pole is entirely in the opposite direction it does not matter; the line of rays is projected all the same in a straight line from the negative.

\section{( $T$ v le conimud.)}

\section{NOTES}

THE following grants have just been made from the Research Fund of the Chemical Society: $-30 l$. to Mr. W. Whitley Williams for experiments on an improved method of organic analysis; 25l. to Mr. M. M. Pattison Muir, of Caius College, Cambridge, for determining the physical constants and chemical habitudes of certain bismuth compounds; $\mathbf{I} 5 l$. to $\mathrm{Mr}$. J. M. Thomson for experiments on the action of isomorphous bodies in exciting the crystallisation of super-saturated solutions; $50 \%$. to Dr. Wright for continuing his researches on chemical dynamics; 25l. to Mr. F. D. Brown for continuing his researches on the theory of fractional distillation; $30 \%$, to $\mathrm{Mr}$. Bolas for an investigation of certain chromium compounds; $20 l$. to $\mathrm{Mr}$. F. R. Japp for an investigation of the action 'of organo-zinc compounds on quinones; and Iool. (the De Ia Rue donation) to Dr. H. E. Armstrong for the determination of certain physical properties, especially refractive indices, of typical chemical compounds. Dr. De la Rue has announced his intention of presenting the fund with another $100 l$. This will be the third donation of that amount which the fund has received from him.

THE Council of the Royal Society of Edinburgh have decided to award the Makdougall Brisbane Prize for the biennial period $1877-78$ to Prof. Geikie for his "Memoir on the Old Red Sandstone of Western Europe," Part I., published in the Ssciety's Transactions, and forming part of his valuable contril.utions to geology.

General MYer, of the U.S. Signal Corps, has arrived in Paris from Rome, on his way to London, where he will have an interview with the Meteorological Board for the purpose of establishing an under:tanding in matters of common interest, especially on the subject of exchanging telegrams with America, so that both nations may enjoy a daily summary of the weather on each continent.
M. Lissajous has been elected a Foreign Corresponding Member in the Paris Academy, Section of Physics, in place of the late Dr. von Mayer.

Dr. Faivre, the Dean of the Lyons Faculty of Sciences, has been run over by a cart when conducting a number of pupils to a botanical excursion. His constitution was so dreadfully shaten that he died after a few days of suffering. Dr. Faivre was opposed to the Darwinian theory, and has published books against the mutation of species. His most important publication was a review of Goethe's scientific works.

THE collection of living reptiles in the Jardin des Plantes, Paris, has just received an interesting addition in the shape of three living examples of the rare East-Indian serpent known to naturalists as Acrochordus javanicus. These snakes belong to quite a peculiar type of the Ophidian order, and are, in fact, truly fresh-water snakes, living among rocks wholly immersed beneath the surface, and but seldom rising up to inhale air. They are quite harmless, and allow themselves to be handled without difficulty. The food of the Acrochordus is supposed to be fruita most anomalous diet for a snake, if this is really the case, but the specimens at Paris have not yet shown a taste for eating anything.

WiTH reference to a recent note, the Abbé Moigno writes us from Rome that he has not resigned the editorship of Les Mondes, which he has edited for twenty-seven years. He has gone to Rome to lay at the feet of the Pontiff the results of many years laborious work, but will return as he went, not a Cardinal, but the doyen of scientific journalists, eager for progress in all directions. We sincerely wish the Abbé rrany more years to carry on the work of editing his well-known journal, that bas for so long done good service to science.

AMONG other recommendations made at the recent meeting of the International Meteorological Congress was the adoption of the meridian of Greenwich as the starting-point for the construction of synoptic weather charts. In the event of another meridian being used in the construction of meteorological charts the Con. gress recommended that the difference of longitude between the meridian employed and that of Greenwich should be stated on the chart.

A TERRIFIC thunderstorm broke over Paris on June 28 at six o'clock in the morning. There were a number of casualties; one of the most singular occurred in a room in the rue de Clichy, No. 34, where two old ladies live. One of them was drinking milk from a cup, which was knocked from her hands and could not be found, although the lady escaped unhurt. In the rez.de chaussée was the shop of a chemist, where a number of bottles were broken, and in the same house a bed, where a woman had taken refuge, was cut into two equal parts.

IN a balloon ascent which took place at Rouen on June $\mathbf{I}_{5}$ last with a large balloon, the occupants of the car found at I 2,000 metres from the earth a cloud where the cold was so intense that small icicles were seen suspended to the beards and moustaches of the travellers.

THE Parkes Museum of Hygiene, founded as a memorial of the late Dr. E. A. Parkes to promote the study of all matters bearing upon the health of the community or the individual, was formally opened on Saturday by the Home Secretary, in the rooms on the council of University on the top floor of the building lent by the council of University College until separate and suitable premises can be obtained. At present there have been brought together apparatus, specimens, boolis, reports, and drawings illustrative of matters connected with engineering and local hygiene; architecture, including general designs and details of buidings, methods of
constructing hospitals, blocks of artisans' dwellings, \&c., with 